
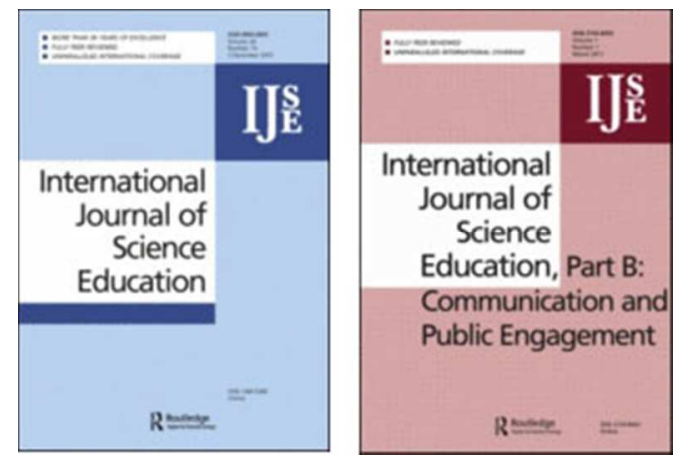

\title{
Participation in informal science learning experiences: the rich get richer?
}

\begin{tabular}{|r|l|}
\hline Journal: & International Journal of Science Education \\
\hline Manuscript ID & TSED-2016-0571-B.R2 \\
\hline Manuscript Type: & Research Paper \\
\hline Keywords: & equity, informal education \\
\hline Keywords (user): & STEM learning ecosystem \\
\hline
\end{tabular}

SCHOLARONE ${ }^{m}$

Manuscripts 


\begin{abstract}
Informal science learning experiences have been found to provide valuable opportunities to engage with and learn about science and, as such, form a key part of the STEM learning ecosystem. However, concerns remain around issues of equity and access. The [project name] study builds upon previous research in this area and uses the construct of 'science capital' to understand and support science engagement among young people, particularly those historically marginalised from science. Drawing on survey data from nearly 6000 children ages 11-16 in England, we investigate who participates in particular areas of informal STEM learning outside of the science classroom. Survey findings are illustrated by interview data from the same project. Analyses suggest that overall participation in different types of informal science learning experiences ('informal' learning experiences, 'everyday' learning experiences, and school-led enrichment) varies. Generally, students from more privileged social backgrounds participate more, but with further ethnic and gender patterns between different ISL activity types. These differential patterns of participation highlight how some areas of the ecosystem (e.g. 'everyday' learning experiences) are more accessible, while others (e.g. in designed spaces and school-led enrichment) could do more to address inequities in participation.
\end{abstract}

Keywords: science learning ecosystem, learning outside the classroom, equity, participation 


\section{Participation in informal science learning experiences: the rich get richer?}

Participation in science has been an ongoing subject of international concern among science educators and policy makers for many years (European Commission, 2004; National Science Foundation, 2016). Despite attempts by government and educational institutions within and outside of the formal sphere to widen participation in science, particularly by those from underrepresented groups, it is a field that remains marked by privilege.

Informal science learning experiences, which can include a range of experiences, including those in designed settings such as museums, science centres or aquaria, have been found to provide valuable opportunities for people to engage with and learn about science (Bell, Lewenstein, Shouse, \& Feder, 2009; Stocklmayer, Rennie, \& Gilbert, 2010). These 'informal' experiences are recognized as complementing and extending learning opportunities for young people beyond those available in school (Reiss et al., 2016; Russell, Knutson, \& Crowley, 2013). That is, learning opportunities occur both inside and outside of the classroom, and together can be conceptualised as a learning ecology or ecosystem. Barron (2006) defines a learning ecology as 'the set of contexts found in physical or virtual spaces that provide opportunities for learning. Each context is comprised of a unique configuration of activities, material resources, relationships, and the interactions that emerge from them' (p. 195). The ecology/ecosystem metaphor has also been employed by a number of researchers with reference to STEM learning in particular (e.g. Falk et al., 2012; Russell, Knutson, \& Crowley, 2013; Traphagen \& Traill, 2014). ${ }^{\text {i }}$ The STEM learning ecosystem is comprised of schools, community settings (e.g. afterschool clubs), designed spaces (such as science museums) and other informal experiences across home and community environments (Falk et al., 2012; Traphagen \& Traill, 2014). 
While not necessarily employing the ecosystem metaphor per se, previous studies have highlighted the interrelated nature of learning experiences across various contexts. For instance, research has documented the way in which families bring their previous experiences and learning to bear in making meaning during a visit to a science centre (Zimmerman, Reeve, \& Bell, 2010), as well as the way in which youth see science across a range of contexts and practices, both formal (in school) and informal (Bell, Bricker, Reeve, Zimmerman, \& Tzou, 2013; Zimmerman \& Bell, 2014). In addition, learning from an experience such as a school trip to a museum or science centre is maximised when supported by other aspects of the ecosystem, such as pre- and post-visit classroom activities (c.f. Author 1 \& Colleague 1, 2007; Author 1 \& Colleague 2, 2008). Other, ethnographic, research has also captured the way in which families utilise a range of resources, including museums, to support learning (Ellenbogen, 2002). However, although individuals may encounter and utilise a variety of contexts and experiences as resources for learning, such opportunities are often uncoordinated (Bell, 2013). In light of this discoordination, to which individuals from more disadvantaged or disempowered groups may be particularly vulnerable, recent research, often drawing on theories of interest development (Hidi \& Renninger, 2006), has been attempting to trace the way in which interest in science can be triggered by everyday activities and then may be extended and strengthened. This work involves retrospective interviews with adults working in science and engineering, as well as qualitative research with young people currently engaged in STEM-related activity outside of the classroom, and aims to explore the ways in which resources (social, cultural, material) form a pathway to support interest development (Crowley, Barron, Knutson, \& Martin, 2015). Insights from this research, ultimately, hold promise for highlighting ways in which different organisations may be able to work together more effectively, to form pathways supporting science-related learning that 
is truly 'life-wide' (Banks et al, 2007; Bell et al., 2013), as well as open to individuals from diverse backgrounds.

Despite efforts to encourage development of science-related interest and engagement, particularly among individuals from groups historically marginalised from science, access to all areas of the ecosystem continues to be unequal, leading to concerns about who participates in activities designed to promote interest in science, enjoyment of science and ultimately science literacy in and outside of school contexts (Bell, 2013; Bell, et al., 2009; Dawson, 2014a; Feinstein \& Meshoulam, 2014). Indeed, it is this unequal access that partly motivates research on learning pathways. In addition, substantial research has been devoted to issues of equity and access to designed spaces (e.g., Author 2 et al., 2016; Dawson, 2014a; Feinstein \& Meshoulam, 2014), while other efforts to address such issues have focused on the potential role of community and after-school programs (e.g. Calabrese Barton \& Tan, 2010; Gonsalves, Rahm, \& Carvalho, 2013), or even opportunities to develop 'everyday expertise' (Bell et al., 2013). This paper reports on data from part of a larger, five year project which is aligned with these concerns and which aims to help students and their families find science engaging, interesting and useful for improving their life chances. While much of this project focuses on work with teachers and classroom pedagogy (the schools element of the ecosystem), the current paper draws on a subset of project data, primarily quantitative, to address the following research question: Who participates and in which aspects of the STEM learning ecosystem outside of the science classroom?

\section{Conceptual framework}

The conceptual framework underpinning our work draws on Bourdieu's theory of social reproduction, in which social relations of privilege and subordination are understood as 
reproduced through the interaction of habitus (socialised dispositions), capital (economic, social and cultural resources) and field (social context, produced through relations of power) (e.g. Bourdieu 1977; 1984). Bourdieu's concept of capital was formulated predominantly within the context of the arts, for instance, he delineates cultural capital in terms of artistic, aesthetic preferences (e.g. views on paintings, participation in les beaux arts, like opera). However, we have extended his ideas through the notion of science capital, which we propose as a conceptual tool for referring to a range of science-related cultural and social capital that an individual may possess. This is because, not least as Prieur and Savage (2013) explain, 'Given the scale of technological and social change, it would be remarkable if Bourdieu's account of cultural capital continued to exist in an unchanged form' (p. 249).

More specifically, science capital can be viewed as consisting of science-related cultural capital (including scientific literacy and science dispositions, knowledge of transferability of science skills and qualifications); relevant behaviours and practices (e.g. engagement with science-related media, informal science experiences), and forms of social capital (e.g. parental scientific knowledge, talking with others about science, receiving encouragement from others to continue with science) (Author 2 et al.; Author 1 \& Author 2, 2016). Previous research also suggests that science capital is closely related to planned future participation in science (e.g. to study post-compulsory science or aspire to a science-related job) as well as to science identity, or seeing science as 'for me' (Author 2 \& Author 1, 2016; Carlone \& Johnson, 2007).

The extent to which an individual may see particular activities - or ecosystem elements as 'for me', and the degree of access they have to such activities, is influenced by a number of factors, including the science capital they possess and the extent to which it is valued within particular fields (e.g. school science education). For instance, how often a child visits a science 
centre or museum is not only driven by their interest in such an activity, it is also influenced by physical proximity to such a venue, possible admission charges (and other associated costs), the interest of other family members (who may want to spend leisure time in different ways) and the time available to visit, as well as perceptions of whether such as space is 'for me' or not. A child could attend on a school trip, but such opportunities are also constrained by costs/budget availability, as well as pressures of accountability and performativity within the school system. Even if a child is able to visit, how deeply they engage with what they encounter and their meaning making practices during the experience (and, consequently, what they gain from it) is strongly influenced by the cultural and intellectual tools they and their fellow visitors (peers, family) bring and the extent to which these are recognised by the museum context (c.f. Author 2 et al., 2016; Seakins et al., 2016). Importantly, such spaces often send messages to visitors about who they are 'for', thus reinforcing perceptions about whether they are for 'people like me' or not (Dawson, 2014a, b). In sum, a child's learning ecology - and what they are able to gain from it - is influenced by far more than their interest: it is fundamentally shaped by physical, economic, social and cultural factors, including their science capital, that combine to open up or shut down access and participation. In this paper, then, we explore who does seem to have access - who does participate - in elements of the STEM learning ecosystem outside of the classroom.

\section{Methods}

The wider project from which these data are drawn involves a partnership between a university, a science museum and a funder. It employs a mixed-methods approach in seeking to understand and support engagement with science among young people, particularly those from groups historically marginalised from science. The quantitative element of this research involves an annual survey of young people, while qualitative methods (e.g. focus groups, observations, 
interviews) were employed to capture more fully participants' experiences of the various activities that comprised the overall project (which included classroom activities, school and family museum visits, and teacher professional development).

\section{Survey instrument}

The initial development of the survey was informed by findings from a previous project (c.f. Author 1 et al, 2011; Author 1 \& Author 2, 2015), which explored children's aspirations in science from ages 10-14, while the survey reported on in this paper has been refined through four successive years of the [current] project (2013 to 2016). The survey instrument itself consists of items corresponding to demographic/background information, such as gender, ethnicity, cultural capital $^{\mathrm{ii}}$, parental employment, and set (or track) in school subjects (as a proxy for attainment). It also contains items corresponding to dimensions of science capital, namely, scientific literacy, scientific-related dispositions/preferences (e.g. attitudes to science and scientists, perceptions of school science and teachers), knowledge about the transferability of science qualifications (in the labour market), consumption of science-related media, participation in out-of-school science learning activities, and science-related social capital (i.e. knowing individuals working in science-related jobs, talking with others about science).

Drawing on our conceptual framework, the survey attempts to capture aspects of habitus (e.g. dispositions/preferences) and capital (e.g. knowledge, social capital) and how these are manifested in the field of science and ISL. We acknowledge that our operationalisation of these constructs is necessarily imperfect but we also want to highlight the way in which our survey instrument was theoretically informed. For instance, it is not possible to measure field in any objective sense - the closest we can come is to measure student views and experiences of participation in different fields (e.g. science classroom, science museums, etc). These elements 
can, of course, also be considered as aspects of students' learning ecosystems. Further details of the development and validation of the survey are reported elsewhere (Author 2 et al., 2015) and a copy of the full instrument is available from the authors.

In this paper, we report on data from the most recent administration of the survey (201516), because it contained the greatest number of items corresponding to the research question about participation in STEM-related activity outside of the classroom.

\section{Participating students}

This survey was completed by 5961 students from 16 secondary schools in England. We do not claim that these schools are representative, rather they were specifically targeted as part of the wider project because they tend to serve students from communities who have traditionally had low levels of participation in science. Background information about these students is summarised in Table 1. This table also includes information about cultural capital, which was a measure (based on parental university attendance, leaving school before age 16, number of books in the home and museum visitation) that had been developed and utilised in multiple surveys in the current project and others. Students were also asked which sets (or groupings/tracks) they were in for science as a proxy for science attainment.

---- Insert Table 1 about here ----

As noted above, although this paper draws mainly on quantitative data, qualitative data was also collected in the course of the project, which is used to illustrate the study findings which are based on quantitative data. In particular, we draw upon a set of data collected throughout the project including 29 discussion groups with students, 16 interviews with teachers, 20 individual interviews with students and 14 interviews with family members (generally parents) of those students. The students were in Years 7 (ages 11-12), 8 and 9 and were from 
seven schools across England (a subset of those completing the survey). They were primarily from working-class families with a range of ethnic backgrounds. While the discussion groups and interviews covered a range of topics including experience of science in and outside of school, participation in leisure activities (science-related and not) and broader views of science, the excerpts we utilise pertain to the ways in which students and their families participate (or not) in science-related activities outside of the classroom.

\section{Analyses}

Data analyses were conducted in a manner similar to previous administrations of the survey. First, reliability and validity analyses were conducted, using principal components analysis (PCA) and Cronbach's alpha to determine internal consistency and unidimensionality of scales. Three of the components that emerged from this analysis correspond to participation in sciencerelated activity outside of the classroom: 'Informal' science activities, 'Everyday' science engagement, and School-led science enrichment. ${ }^{\text {iii }}$ Second, all of the components that emerged from the first set of analyses were used to form composite variables (by taking scores on the 5point Likert scale items and averaging across items). These variables were then utilised to explore patterns in children's responses, including by gender, ethnicity and cultural capital. More specifically, descriptive and multivariate analyses were used to gain an overview of the data. Next, multilevel modelling analyses (a form of regression analysis that accounts for students being nested within schools) were conducted to further investigate factors related to students' participation in science-related activities outside of the classroom. ${ }^{\text {iv }}$ In particular, three models were constructed, one with 'Informal' science activities as the dependent variable, one with 'Everyday' science engagement as the DV and one with School-led science enrichment as the 
DV. These analyses identified which variables are most closely related to each of the three composite dependent variables.

As noted previously, qualitative data was collected in the context of the larger project. Data from discussion groups as well as from individual interviews with teachers, parents and students was reviewed to find responses to questions about students'/families' participation in science-related activities outside of school (clubs, school trips, family museum visits, other visits, media use, and so forth). Responses were broadly categorised as to type of activity, such as 'everyday' (e.g. watching TV), 'informal' (e.g. museum visits) or school-led (e.g. school trips). These responses were further scrutinised to try to gain a sense of the range of views expressed. Due to the semi-structured nature of the interviews and discussion groups, there was variation in the questions asked and data on these topics was not collected in a systematic way. Thus, although it could be broadly categorised and the excerpts used reflect a range of views expressed by participants, we cannot claim they are representative of the perspectives held by all participants. Consequently, the quotes are used for illustrative purposes, to add richness to the survey data and exemplify the quantitative findings.

\section{Findings}

\section{Types of engagement}

Survey analysis revealed three components in the data that correspond to different types of engagement with elements of the STEM ecosystem outside of the classroom (or aspects of the field), and these form the focus of our quantitative analyses. These were School-led science enrichment (including taking science-related school trips, attending visitor talks or presentations about science, or going to lunchtime/after-school science clubs), 'Informal' science activities (including visiting zoos and aquaria, taking nature walks, doing experiments, and going to 
science centres or museums), and 'Everyday' science engagement (including watching science TV programmes or popular programmes with science in them, going online to find out about science, and talking with others about science). These three components had Cronbach's alphas of .742, .814, and .793, respectively, which can be considered good (Field, 2013). Although the items in the 'everyday' science engagement component might be viewed as elements of the informal science ecosystem, the PCA indicated that they form a separate component. (Please see Appendix A for detail of the PCA.) We use the term 'everyday' to denote them because they would seem to require minimal to no extra preparation, in contrast to the items in the 'informal' science activities component, which involve travel and/or the acquisition of more specialist materials. Additionally, although the overlap is not perfect, many of the items in each of the three components map onto the various venues/configurations for learning science in informal settings: everyday settings, designed settings and programmes (Bell et al., 2009).

Perhaps not surprisingly, overall, students report somewhat more engagement in 'everyday' science activities than in 'informal' science activities, while participation in schoolled science enrichment lags behind. (See Table 2 below for the means and standard deviations of these variables). For instance, looking more closely at the items comprising the 'Everyday' science engagement composite variable, over $40 \%$ of students report watching science TV programmes at least once a month, and this figure rises to $57.1 \%$ for students watching popular programs with at least some science content (e.g. medical dramas, forensic programmes). Nearly $2 / 3$ report having gone online at some point to look up science content, and over half (52.1\%) responded that they talk with others about science (outside of the classroom) at least once a month. Reported participation in the activities comprising the 'informal' science composite stands in contrast, with approximately half of students reporting 'never' having done a science 
kit or experiment at home. Additionally, $47.8 \%$ of students replied that they have 'never' visited a science centre or museum.

While the above data are consistent with concerns around access to informal science activities (and designed spaces in particular) expressed in the literature (e.g. Bell et al., 2009; Dawson, 2014a), schools have often been regarded as a potential route by which individuals may be able to gain access to participation in science outside of the classroom (albeit schoolorganised). However, our data suggests that - in the schools we surveyed at least - such potential may be underutilised. Looking at the items in the School-led science enrichment composite variable, just under $55 \%$ of students report that they have never taken a science-related school trip, and a further $19 \%$ have only done so once, over a year in the past. Nearly $70 \%$ have never had a visitor talk or presentation about science (or not that they recall!)

\section{Who participates? And in what?}

Although there are differences in the types of out-of-classroom activity students engage in overall, several of the patterns of who is participating are quite similar across these elements of the STEM learning ecosystem. Table 2 below presents the mean scores for various groups (standard deviations in brackets) on each of three composite variables corresponding to the three activity types. Note that the scores could range from 1-5 (with 1 representing very little or no participation and 5 representing very frequent participation).

---- Insert Table 2 about here ----

Multivariate analyses highlight that students with higher levels of cultural capital, those attaining more highly in science, and those with family members working in science-related jobs were more likely to participate in these various activities. More specifically, a series of one-way ANOVAs indicated that students with higher levels of cultural capital reported greater 
participation in 'informal' science activities, $\mathrm{F}(4,5687)=316.096, \mathrm{p}<.001$; in 'everyday' science activities, $\mathrm{F}(4,5733)=169.064, \mathrm{p}<.001$; and in school-led science enrichment, $\mathrm{F}(4$, $5769)=91.431, \mathrm{p}<.001$. (Post-hoc Bonferroni comparisons also reflected that the differences among all groups were significant.) Likewise, higher attainment corresponded to greater participation: students in higher sets for science reported more participation in 'informal' science activities, $\mathrm{F}(3,5682)=39.585, \mathrm{p}<.001$; 'everyday' science activities, $\mathrm{F}(3,5728)=64.361, \mathrm{p}<$ .001 ; and school-led science enrichment, $\mathrm{F}(3,5764)=22.721, \mathrm{p}<.001$. In addition family also related to participation, with students who had a family member working in science being more likely to participate in 'informal' science activities, $\mathrm{F}(2,5687)=80.703$, $\mathrm{p}<.001$; 'everyday' science activities, $\mathrm{F}(2,5733)=190.946, \mathrm{p}<.001$; and in school-led science enrichment, $\mathrm{F}(2$, $5769)=77.359, \mathrm{p}<.001$.

With respect to age, although means of reported participation generally decrease as students get older for both 'informal' science activities, $F(4,5687)=38.016, \mathrm{p}<.001$, and for school-led science enrichment ${ }^{\mathrm{v}}, \mathrm{F}(4,5769)=25.575, \mathrm{p}<.001$, this is not the case for participation in 'everyday' science activities, where engagement is fairly consistent over the years (and even increases slightly, though this increase is not statistically significant).

The pattern of participation by gender is somewhat more complex, however. Although boys score more highly than girls on the composite variables reflecting school-led enrichment, $\mathrm{t}(5189)=2.528, \mathrm{p}<.05$, and 'everyday' science-related activities, $\mathrm{t}(5185)=4.256, \mathrm{p}<.001$, the difference between them on the 'informal' science activities component is not significant $(\mathrm{p}=$ .621). (Recall that each of these three composite variables, reflects a range of activities - so a lack of gender difference on a variable overall does not necessarily translate to a lack of difference in participation in each of the activities comprising the variable.) Likewise, patterns of 
participation by ethnicity are also not straightforward. For instance, ANOVA analyses suggest differences by ethnic background in terms of their reported participation in school-led science enrichment, $\mathrm{F}(6,5767)=20.757, \mathrm{p}<.001$, and in 'everyday' science activities, $\mathrm{F}(6,5731)=$ $16.625, \mathrm{p}<.001$, with post-hoc Bonferroni comparisons highlighting that White students are significantly less likely to participate in both, compared with students from South Asian and Black ethnic backgrounds. In contrast, Black students are less likely than White, South Asian, and Middle Eastern students to participate in 'informal' science activities, $F(6,5685)=5.575$, $p$ $<.001$.

\section{Whose ecosystem? Inequalities in informal science learning participation}

Although the differences described in the previous section are intriguing, the large sample sizes mean that even small differences can emerge as statistically significant. Consequently, multilevel modelling analyses were performed, which also account for the fact that students are clustered into schools, and these analyses substantiated the patterns described above. In these analyses, three models were constructed, one each for 'Informal' science activities, 'Everyday' science engagement and School-led science enrichment, which are presented in Tables 3, 4 and 5, respectively. We acknowledge that these three variables would be expected to be closely related to each other and Pearson's correlation coefficients reflect that, indeed, this is the case. ${ }^{\mathrm{vi}}$ However, we feel that there is value in constructing a separate model for each of the three composite variables, in order to gain a fuller picture of similarities and differences among them. Note that for clarity of presentation only variables that are significantly related to a dependent variable (e.g. 'Everyday' science-related activities) are included in the final model for that variable (and presented in the corresponding table). Below, we discuss each model in turn, 
illustrating the overview provided by the MLM for each dependent variable with excerpts from qualitative data collected in the course of the wider project.

\section{Participation in 'informal' science activities: 'They don't go to museums, they don't do things}

\section{like that'.}

---- Insert Table 3 about here ----

The model presented in Table 3 accounted for, or explained, $48.4 \%$ of the variance in the dependent variable ('Informal' science activities). Of the variance explained, $12.2 \%$ was at school level and $87.8 \%$ was at pupil level. The model is consistent with multivariate analyses in reflecting that Black students in particular, as well as those with lower levels of cultural capital, are less likely to participate in 'informal' science activities, and that participation decreases with age. Analyses also reveal that school-led science enrichment is the composite variable most closely related to participation in 'Informal' science activities. The independent variable of participation in 'everyday' science-related activities is also quite closely related to the dependent variable of participation in 'informal' science activities, followed by Valuing museums (which is not surprising, given that the 'Informal' science activities variable includes items related to visits to informal science venues).

Although visits were only some of the activities included in this variable, interviews with students and their families are also consistent with the wider survey data in suggesting that activities such as going to science museums were not something in which most engaged. (Recall that nearly half of respondents said they had 'never' visited a science centre or museum.) This was clearly at least partly due to logistical concerns related to travel and or time, as expressed by some students when they were asked about coming with their parents to an organised family day at the Science Museum: 
I do want to go with my parents, but it's just really long to get there. With a train it's two hours... and you can get confused and take the wrong train and then the next stop could be really long and then if the train takes long to come...

Yeah, my mum would actually really enjoy it. But you know, like, it's really far away so... and parking is a problem.

We was going to [go to the family day at the science museum], but my dad wasn't off, he was still working.

Concerns about the costs of such experiences were also expressed by some students:

We would go to the park, but not things like museums and zoos... 'cause like the money... we like to save it for bigger occasions, do you know what I mean, Miss?

Relatedly, several students were not aware that the museums (the ones involved in this project) were free to the public, which reinforces the perceptual barrier of visiting faced by a number of families. Some students also felt that places like museums were not for people 'like them' (many of whom came from minority ethnic backgrounds):

It was like there was a lot of posh people, not really like other kind of races.

However, although the student expressing the above perspective was not unique in his view, when presented with the possibility that some people felt that museums were for 'posh, White people', a number of students not only disagreed with this perspective but were actually affronted by it:

You don't feel as if you're not, you're different from others, like everyone is there, everyone is welcome to come...

That is a stupid thing to say, I'm sorry... that is racist... I don't think nothing to do with that... I disagree with that, who said that?! 
Nevertheless, the view that science museums are not welcoming to all is consistent with other research highlighting the way in which such spaces are not equally accessible, even once families manage to get there (Author 2 et al., 2016). On the other hand, lack of engagement in informal activities such as museum visits is unlikely to be purely due to an overall lack of interest in or valuing of science. For instance, nearly $2 / 3$ of students in the survey felt that knowledge of science was useful in their daily lives and over half reported that their parents thought science was 'very interesting'. Moreover, some families did engage in science-related visits, such as to city farms:

I went to Grange Farm... because it's free and it's near an Asda.

The above quote was echoed by others and a number of families also seemed to engage in activities such as nature walks. Although, statistically, these items grouped with others such as museum visits on the survey, they are different in being more local and, potentially, inexpensive. This suggests that when science-related activities are more accessible (e.g. local, low-cost, perceived as welcoming), students and their families are more likely to participate. This point is further illustrated by qualitative data around 'everyday' science activities, as we discuss in a later section.

Nevertheless, for some families, engagement in these types of structured activities (whether science-related or not) would simply seem to be off the radar, or not form part of their 'family habitus' (Author 2 et al., 2012). That is, for some families, structured visits are not part of 'who we are and what we do' and the limited leisure time they have is spent visiting family, participating in sports, going shopping and the like:

We never normally go out on special occasions to like, all the zoos and stuff like that, we only go to like the shop.

I would go to my Nan's and then we go shopping on a Saturday. 
That is not to say that these families 'do nothing'. For instance, several parents reported engaging in a range of less structured activities:

Riding bikes, road bikes, and go for long walks, go swimming.

At the same time, these illustrative excerpts from our interview data do echo the quantitative data, suggesting that there may be substantial barriers around accessing some kinds of informal science activities, and that lack of interest is unlikely to play a major role in the reduced levels of participation of some students.

\section{Participation in 'everyday' science activities: 'YouTube videos of like how things work and things like that'. \\ ---- Insert Table 4 about here ----}

The model displayed in Table 4 accounted for $49.8 \%$ of the variance in the outcome variable ('Everyday' science-related engagement), of which $12.7 \%$ was at school level and 87.3\% at pupil level. It also highlights that the variables most closely associated with 'Everyday' science-related engagement are participation in more structured forms of science-related activity ('Informal' science activities), as well as having a strong science affinity and interest in working in science (Science identity). Valuing science is also related, though not as strongly. It is also noteworthy that although some background variables (such as ethnicity and cultural capital) are reflected in the model, fewer categories are included and the effect sizes are quite small, suggesting that the relationship between background characteristics and this dependent variable ('Everyday' science-related activities) is not as strong as that between those characteristics and participation in more structured 'informal' science activities.

Additionally, the interviews were consistent with the quantitative data in illustrating that 'everyday' kinds of science engagement, and watching television in particular, appeared to be 
more widespread, compared with participation in 'informal' science activities. Students did report watching science videos online (e.g. on YouTube) and when asked about the kinds of science-related activities they engaged in outside of school, students inevitably mentioned TV programmes both they and other family members watched. Several reported watching sciencerelated programmes:

Student 1: I once saw, you know, like Steven Hawkins' like theories and stuff, 'cause I like seeing like how and why they've done that and it just gives me like a brief idea.

Student 2: I like the Brian Cox documentaries, they're really fun to watch.

Nature documentaries, especially animal-related, were particularly popular among students and their families:

When I was younger I used to watch this programme... I can't remember what it was called but it was about like wildlife... I was watching... I can't remember what it was called, it was on BBC1. And it was something about bees and all different animals every week... every Sunday it was, and I used to watch it.

Uh... we watch those documentaries that come on... the narrator, he's dead... he's kind of like... he's well known, and he makes these animal programmes and some science ones as well ${ }^{\mathrm{vi}} \ldots$

Some students were even able to articulate what they felt they had learned from popular programmes such as the Big Bang Theory:

I never knew what a theoretical physicist was... So I learnt that... It's somebody who like tests out theories that could possibly be correct or right.

Thus, it would seem that when science-related activities are readily accessible - such as via television or the Internet, students and their families are more inclined to engage, reinforcing the argument that lack of participation in particular kinds of science activities outside of the 
classroom (e.g. science museum visits) is not due to a lack of interest in or enthusiasm for science.

\section{School-led science enrichment: 'We were lucky to be chosen'.}

---- Insert Table 5 about here ----

The model above accounts for $29.5 \%$ of the variance in the outcome variable (school-led science enrichment), with $12.0 \%$ of the variance occurring at school level and $88.0 \%$ at pupil level. The model reflects that participation in 'Informal' science activities is the independent variable most closely related to the dependent variable of participation in school-led science enrichment. We find it intriguing that although the proportions of variance accounted for at school and pupil level are comparable across the three models (roughly $12 \%$ and $88 \%$, respectively), the model for school-led science enrichment accounts for less variance in the outcome variable than the other two models. This may be connected to what provision is offered by different schools but as this data is not available, it remains a question for future research.

Nevertheless, while it is clear from the MLM analyses, then, that some out-of-school science activities are more accessible, to a more diverse range of individuals, than others, it would seem that schools are well-positioned to provide science enrichment to students from a variety of backgrounds, given the populations they serve. However, our survey data suggests that a minority of students participate in school-led science enrichment (e.g. fewer than half report having taken a science-related school trip), and that students with, for instance, higher levels of cultural capital and higher attainment are more likely to participate. That this might be the case is also hinted at in the interviews we conducted with students, in which the lack of, for instance, science-related school trips was evident. That is, while many students reported having been on 
school trips to places like science museums and science centres (as well as other museums), most of these trips seem to have taken place in primary school:

We have to go, like, three times every year, I think, in my primary school.

I've been there about 20 times in primary.

Indeed, several of the students we interviewed remarked upon the special nature of being invited to go on a school trip:

Student 1: And we were lucky to be chosen because I don't, I think secondary schools don't normally go to trips.

Student 2: We were given the responsibility.

Student 1: Yeah, the responsibility to take part.

Of course, the reasons for schools taking fewer trips in secondary school have been well documented (e.g. Author $1 \&$ Colleague 2, 2008; Bell et al., 2009), and these are echoed by teachers from two of the schools participating in the current project:

I'm a little bit worried about taking them out and, you know, what if something goes wrong? In some instances, taking them out of school, as soon as you do that, you've got to put in a lot of planning and preparation and effort and sometimes you just feel like massive amounts of workload and ultimately, once you've filled in a risk assessment and got the permission to go out and organise letters and organise permission slips, you know, done everything, is it going to then be worth it?

The curriculum restricts us a bit in terms of what teachers are being asked to do - there's a massive pressure on teachers to achieve target grades. That's often at the expense of broadening the experience of the students. We've had to fight to get them out to do this and one or two other things. 
Teachers did report a variety of science enrichment (and other) activity that was offered at their schools, such as special events, challenge days, clubs, CREST awards ${ }^{\text {viii }}$ and so forth. However, most students participating in such activities were higher attaining - the activities were either not offered to, or were certainly not accessed by, other groups of students.

We've got the G\&T [Gifted \& Talented], so they do CREST awards and things like that.

I'd say generally a lot of the stuff we do are geared towards the higher ability and I do think there's perhaps a lack of opportunity there for the lower ability pupils.

Nevertheless, there is potential for school-led science enrichment to open up opportunities for students from more diverse backgrounds to engage with science. As reflected in Table 5, Black, as well as Asian, students were more likely than White students to report participating in school-led science enrichment. Moreover, although students with very high cultural capital also report more participation, cultural capital, as well as attainment, did not feature as strongly in this model. This suggests that if schools are able to open up such opportunities more broadly, more students will engage - they can serve as a route into science for a wider range of students.

\section{Discussion}

The findings presented in the previous sections highlight the different types of science-related activities in which students engage outside of science lessons, namely 'everyday' science engagement (e.g. watching television, talking with family/friends about science), 'informal' science activities (e.g. visiting a science museum or zoo, performing experiments at home) and school-led science enrichment (e.g. science clubs, school trips). These various activities are often grouped together under the banner of 'informal science learning experiences' and engagement in such activities can support similar outcomes, such as knowledge and skills development, supporting interest, and reinforcing a science learner identity (Author $1 \&$ Colleague 2, 2008; Bell et al., 2009). However, our analyses reinforced that there is also value as considering these 
activity types as distinct elements in the STEM learning ecosystem (Barron, 2006; Falk et al., 2012; Russell, Knutson, \& Crowley, 2013). At the same time, we argue that there are benefits to not considering each activity within these broader categories ('informal', 'everyday', school-led) in isolation. That is, previous research, primarily qualitative and sometimes ethnographic in nature (e.g. Calabrese Barton \& Tan, 2010; Ellenbogen, 2002; Zimmerman \& Bell, 2014; Zimmerman, Reeve, \& Bell, 2010), has provided strong evidence of the way in which students experience science outside of the classroom - as a set of experiences which mutually influence each other. Our findings build on this research quantitatively, with a larger sample size, indicating the way in which various kinds of activities group together. While the groupings that emerge from our analyses are not surprising, they are conceptually useful in affirming patterns of participation that are suggested by previous, qualitative research.

Our quantitative analyses also build on previous studies by reflecting that overall participation in science outside the classroom varies by type of activity. Our analyses indicate that participation in 'everyday' science activities is quite common, while participation in more structured activities, which often require more planning and potential expense ('informal' science-related activities) is less typical. Moreover, analyses reflect that participation in schoolled science enrichment is actually relatively rare, even though the young people responding to the survey all attend school and thus, in principle, should be able to access much of this activity. Put simply, participation in different areas of the STEM ecosystem varies considerably, notably across different forms of 'informal' science learning contexts, which highlights important equity issues.

Due to the size of our sample, our data enabled us to explore whether groups participate differentially in the STEM learning ecosystem. Although the three survey components - which 
correspond to various elements of the STEM ecosystem - are related, not only does overall participation in their constituent activities vary, but who participates also varies, particularly by gender and ethnicity. Our findings show that higher attaining students and those with more cultural capital are more likely to participate in all three types of activities. In contrast, although our analyses reflect the way in which reported participation in 'informal' science activities and school-led science enrichment generally diminishes with age, no such decrease is evident for participation in 'everyday' science activities. Such a pattern is consistent with a picture of increasing pressures on students' time as they progress through secondary school, leaving less time for more structured forms of science engagement ('informal' science activities). It also echoes descriptions of increasing performativity demands within schools, leading to more time devoted to test preparation as students get older, which may limit opportunities for school-led science enrichment. Nevertheless, that participation in 'everyday' science activities does not decrease also reflects that interest in science per se may not be decreasing - rather, it may be that the opportunities or capacity to engage in science-related activities outside of the classroom diminish over time. It also highlights the accessible nature of TV, reminding us that it has an important role in the STEM ecosystem.

That some types of activity are more accessible than others is also indicated by patterns of participation by ethnicity, with Black students more likely to participate in 'everyday' science activities and school-led science enrichment, while being less likely to participate in 'informal' science activities. This pattern also suggests that Black students' lack of participation in structured 'informal' activities is likely not due to a lack of interest. Excerpts from interviews conducted in the course of the wider project augment this picture, by highlighting the kinds of activities (those comprising the 'everyday' science engagement component) in which families 
participate and enjoy and flagging up why some kinds of activities - namely visits to museums and science centres, as well as some school-led activity, are not as accessible. That is, the findings reflect the way in which some aspects of the STEM ecosystem (i.e. some designed spaces) do not offer all individuals equal opportunity to participate and, by so doing, to perform themselves scientifically (Carlone, Scott, \& Lowder, 2014). These findings chime with research highlighting the way in which designed spaces are often elitist, reflecting dominant group values and practices, and consequently experienced as 'fish out of water' by minoritised groups, who are also subject to greater pressures on time and resources due to structural inequalities (e.g. Dawson, 2014a, b; Feinstein \& Meshoulam, 2014). However, these findings also add to our understanding of the STEM ecosystem more broadly, by drawing attention to those arenas (e.g. 'everyday' science activities) which are more accessible, as well as those which should be accessible (via schools) but are currently falling short of their potential. That is, the findings point towards opportunities within the STEM ecosystem where individuals' interests in science might be built upon to support participation in other areas, including the classroom.

From a theoretical standpoint, the findings highlight the uneven or inequitable distribution of science capital across different groups. Elsewhere, we have argued that participation in science-related activities ('what you do'), is a key element of science capital (Author 2 et al., 2015). Analyses suggest a strong relationship between opportunities to engage with science outside of the classroom and an individual's identification with science and sense of it being 'for me' (habitus). Thus, our analyses highlight some challenges for ISL educators and providers, such as how participation is mediated by inequalities in capital between different social groups and how students' experiences and perceptions of ISL will be shaped by the extent of the 'distance' between their habitus (and capital) and the field of ISL. Yet our work also 
suggests that ISL experiences may be a valuable form of capital, hence we argue for the importance of ISL seeking to broaden its accessibility, nature and scope, so that more (and more diverse) young people can come to see ISL and science as being 'for me'.

\section{Limitations}

While our dataset enables us to extract some broader patterns in a way that is not possible with qualitative data, informing us as to whether there are patterns of participation across larger groups, it does not enable us to explore linkages among these types of activities. Work on learning ecologies has highlighted the way in which activities can be interconnected and build on each other to support the development of interest and expertise (Barron, 2006), but our dataset does not afford such explorations. In addition, in the survey, we were necessarily limited as to the types of activities could be included, and most of these were related to science rather than to other aspects of STEM (e.g. mathematics activities). So, although we discuss the 'STEM' learning ecosystem, of which science is clearly a part, we would urge caution in generalising too widely from our data.

Relatedly, quantitative data can only tell us about broader patterns of participation, but not about how they link together from perspective of the learner. Our qualitative data does provide richness to the picture but was not collected with the aim of identifying how individuals saw them as linked, and thus precludes that sort of analysis. Also importantly, the data can only tell us about participation, from which we can make inferences about accessibility. That is, the survey did not ask about opportunities or invitations students had to participate, much less about how they felt about such opportunities. Although the qualitative data do provide some insight into this issue (e.g. statements from the teachers about opportunities for gifted and talented 
students to participate in enrichment), further qualitative - and quantitative - work would be useful to unpick the patterns of participation/non-participation seen in our quantitative data.

\section{Conclusions and implications}

In sum, the findings provide a useful insight, based on a relatively large sample of students, into patterns of participation in areas of the STEM ecosystem in England. Such patterns, in turn, have implications for increasing the accessibility of elements within that system. Greater understanding of the types of activities in which individuals from a range of backgrounds participate provides insight into possible points of leverage, or starting points for promoting young people's further engagement with science. That is, these 'everyday' activities, such as watching TV, could be key starting points for developing STEM learning pathways, that might be built upon to further engage individuals, particularly those from groups historically marginalised from science, with STEM.

At the same time, the findings also reflect where more work needs to be doneparticularly in spaces such as museums and science centres, as well as schools, in order to offer diverse individuals the opportunity to perform themselves scientifically and come to see science as not just something in which they have an interest but as something that is 'for me'. (c.f. Carlone \& Johnson, 2007). Our data, reflecting low participation in visits to designed spaces, are aligned with other research that highlights the many barriers some families experience in visiting ISL spaces, and in accessing science content when they do visit. While others have also argued for the need for museums to be more egalitarian and welcoming (e.g. Dawson, 2014a; Feinstein \& Meshoulam, 2014), our data also call on schools to do more as well. We acknowledge that provision of enrichment experiences (such as school trips) can be expensive and timeconsuming, but we urge schools to monitor participation in, not just availability of, enrichment 
activities and not to exclude students who may be lower attaining, for instance. School trips, for example, should not just be used as rewards for high achievement or targeted towards top sets. We argue that supporting schools, which, collectively, serve students across all backgrounds, to ensure enrichment experiences for all students may be a potential 'way in' to widening and deepening engagement with STEM. In other words, helping schools to make more of existing leverage points - or activities in which their students have easy access to and may already participate in, such as watching science-related TV programmes - may be an effective step toward helping more young people participate more fully in the STEM learning ecosystem.

\section{References}

Author 1 \& Author 2. (2015). International Journal of Science Education.

Author 1 \& Author 2. (2016). International Journal of Science Education.

Author 1 \& Colleague 1. (2007). International Journal of Science Education.

Author 1 \& Colleague 2. (2008). Visitor Studies.

Author 1 et al. (2011). International Journal of Science and Mathematics Education.

Author 2 \& Author 1. (2016). Book.

Author 2 et al. (2012). American Educational Research Journal.

Author 2, et al. (2015). Journal of Research in Science Teaching.

Author 2, et al. (2016). Cultural Studies of Science Education.

Banks, J.A., Au, K.H., Ball, A.F., Bell, P., Gordon, E.W., Gutierrez, K.D., . . Zhou, M. (2007).

Learning in and out of school in diverse environments: Life-long, life-wide, life-deep. Seattle: The LIFE Center. 
Barron, B. (2006). Interest and self-sustained learning as catalysts of development: A learning ecology perspective. Human Development, 49(4), 193-224.

Bell, P. (2013). Introduction: Understanding how and why people learn across settings as an educational equity strategy. In B. Bevan, P. Bell, R. Stevens, \& A. Razfar (Eds.), LOST Opportunities: Learning in out-of-school time (pp. 95-98). New York: Springer.

Bell, P., Bricker, L., Reeve, S., Zimmerman, H.T., \& Tzou, C. (2013). Discovering and supporting learning pathways of youth in and out of school: Accounting for the development of everyday expertise across settings. In B. Bevan, P. Bell, R. Stevens, \& A. Razfar (Eds.), LOST Opportunities: Learning in out-of-school time (pp. 119-140). New York: Springer.

Bell, P., Lewenstein, B., Shouse, A., W., \& Feder, M. A. (2009). Learning science in informal environments: People, places, and pursuits. Washington, D.C.: The National Academies Press.

Bourdieu, P. (1977). Outline of a Theory of Practice. Cambridge: Cambridge University Press. Bourdieu, P. (1984) Distinction. London: Routledge.

Calabrese Barton, A., \& Tan, E. (2010). We be burnin'! Agency, identity, and science learning. Journal of the Learning Sciences, 19(2), 187-229.

Carlone, H.B., \& Johnson, A. (2007). Understanding the science experiences of successful women of color: Science identity as an analytic lens. Journal of Research in Science Teaching, 44(8), 1187-1218.

Carlone, H.B., Scott, C.M., \& Lowder, C. (2014). Becoming (less) scientific: A longitudinal study of students' identity work from elementary to middle school science. Journal of Research in Science Teaching, 51(7), 836-869. 
Crowley, K., Barron, B.J., Knutson, K., \& Martin, C. (2015). Interest and the development of pathways to science. In K.A. Renninger, M. Nieswandt, \& S. Hidi (Eds.), Interest in mathematics and science learning (pp. 297-313). Washington, D.C.: AERA.

Dawson, E. (2014a). "Not designed for us": How science museums and science centers socially exclude low-income, minority ethnic groups. Science Education, 98(6), 981-1008.

Dawson, E. (2014b). Equity in informal science education: developing an access and equity framework for science museums and science centres. Studies in Science Education, 50(2), 209-247.

Ellenbogen, K. M. (2002). Museums in family life: An ethnographic case study. Learning conversations in museums (pp. 81-101). In G. Leinhardt, K. Crowley, \& K. Knutson (Eds). Mahwah, NJ: Lawrence Erlbaum Associates.

European Commission. (2004). Europe needs more scientists: Report by the High Level Group on Increasing Human Resources for Science and Technology. Brussels.

Falk, J. H., Osborne, J., Dierking, L. D., Dawson, E., Wenger, M., \& Wong, B. (2012). Analyzing the UK Science Education Community: The contribution of informal providers. London: Wellcome Trust.

Field, A. (2013). Discovering statistics using SPSS (4 ${ }^{\text {th }}$ ed.). London: Sage.

Feinstein, N.W., \& Meshoulam, D. (2014). Science for what public? Addressing equity in American science museums and science centers. Journal of Research in Science Teaching, 51(3), 368-394.

Gonsalves, A., Rahm, J., \& Carvalho, A. (2013). "We could think of things that could be science": Girls' re-figuring of science in an out-of-school-time club. Journal of Research in Science Teaching, 33(8), 901-933. 
Hidi, S., \& Renninger, K.A. (2006). The Four-phase model of interest development. Educational Psychologist, 41(2), 111-127.

National Science Foundation. (2016). Science and Engineering Indicators 2016. Arlington, Virginia: National Science Foundation.

Prieur, A., \& Savage, M. (2013). Emerging forms of cultural capital. European Societies, 15(2), 246-267.

Reiss, M.J., Billingsley, B., Evans, E.M., Kissel, R.A., Lawrence, M., Mujtaba, T., ... \& Veall, D. (2016). The Contribution of natural history museums to science education. London: UCL Institute of Education.

Russell, J.L., Knutson, K., \& Crowley, K. (2013). Informal learning organizations as part of an educational ecology: Lessons from collaboration across the formal-informal divide. Journal of Educational Change, 14(3), 259-281.

Seakins et al., (2016). Manuscript under review.

Stocklmayer, S., Rennie, L., \& Gilbert, J. (2010). The roles of the formal and informal sectors in the provision of effective science education. Studies in Science Education, 46(1), 1-44.

Traphagen, K., \& Traill, S. (2014). How cross-sector collaborations are advancing STEM learning. Los Altos, CA: Noyce Foundation.

Zimmerman, H.T., \& Bell, P. (2014). Where young people see science: Everyday activities connected to science. International Journal of Science Education, Part B, 4(1), 25-53.

Zimmerman, H.T., Reeve, S., \& Bell, P. (2010). Family sense-making practices in science center conversations. Science Education, 94(3), 478-505. 
Appendix A

---- Insert Table 6 about here ----

6 
1

2

3

4

5

6

7

8

9

10

11

12

13

14

15

16

17

18

19

20

21

22

23

24

25

26

27

28

29

30

31

32

33

34

35

36

37

38

39

40

41

42

43

44

45

46

47

48

49

50

51

52

53

54

55

56

57

58

59

60

Appendix B

---- Insert Table 7 about here ----

URL: http://mc.manuscriptcentral.com/tsed Email: editor_ijse@hotmail.co.uk 
Notes

'The terms 'ecology' and 'ecosystem' are used interchangeably in this paper to refer to various contexts, experiences and spaces that provide opportunities for learning.

ii Cultural capital was a composite measure based on items related to parental education (especially university attendance), museum visitation and number of books in the home.

iii The other components were: Science identity and job affinity, Family attitudes and practices (including attitudes to science), Valuing museums, Valuing science, Negative science identification, Science teacher encouragement, Selfconfidence in science.

${ }^{\text {iv }}$ Assumptions for multilevel modelling analysis (e.g. around numbers of respondents) were fulfilled.

${ }^{\mathrm{v}}$ We acknowledge that this trend is (surprisingly) reversed among Year 11 students, whose mean for reported participation in school-led science enrichment does not differ significantly from Year 7 students, but participation does decrease from Years 7 through 10.

${ }^{v i}$ The correlation coefficients for each pair of composite variables are:

'Informal' science activities and 'Everyday' science engagement: 0.523

'Informal' science activities and School-led science enrichment: 0.454

'Everyday' science engagement and School-led science enrichment: 0.417

${ }^{\text {vii }}$ In this example, a student's older brother appears to be referring to David Attenborough, who, at the time of this writing, is still very much alive.

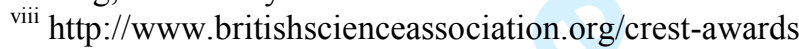


1

2

3

4

5

6

7

8

10

11

12

13

14

15

16

17

18

19

20

21

22

23

24

25

26

27

28

29

30

31

32

33

34

35

36

37

38

39

40

41

42

43

44

45

46

47

48

49

50

51

52

53

54

55

56

57

58

59

60

Table 1

Participating students

\begin{tabular}{|c|c|}
\hline & kground information \\
\hline \multirow[t]{5}{*}{ Year groups } & Year 7 (age 11-12) - 22.0\% (1313) \\
\hline & Year $8($ age $12-13)-24.0 \%(1429)$ \\
\hline & Year 9 (age $13-14)-20.2 \%(1204)$ \\
\hline & Year $10($ age $14-15)-18.3 \%$ \\
\hline & Year $11($ age $15-16)-15.5 \%(922)$ \\
\hline \multirow[t]{2}{*}{ Gender } & Female $-55.9 \%$ \\
\hline & Male $-44.1 \%(2629)$ \\
\hline \multirow[t]{7}{*}{ Ethnicity (self-identified) } & White $-32.1 \%$ (1914) \\
\hline & South Asian - 33.6\% (2000) \\
\hline & Black $-11.1 \%(661)$ \\
\hline & Middle Eastern - 3.6\% (212) \\
\hline & East Asian - $1.1 \%(66)$ \\
\hline & Other or mixed race $-9.7 \%(581)$ \\
\hline & Prefer not to say $-8.8 \%(527)$ \\
\hline \multirow[t]{5}{*}{ Cultural capital } & Very low $-6.9 \%(412)$ \\
\hline & Low $-36.2 \%(2157)$ \\
\hline & Medium $-28.4 \%(1694)$ \\
\hline & High $-17.8 \%(1061)$ \\
\hline & Very high $-10.7 \%(637)$ \\
\hline Attainment (Science & Top set $-41.6 \%(2480)$ \\
\hline \multirow[t]{3}{*}{ set/grouping used as proxy) } & Middle set $-35.6 \%$ (2122) \\
\hline & Bottom set $-9.6 \%(573)$ \\
\hline & No sets for science $-13.1 \%(780)$ \\
\hline
\end{tabular}

URL: http://mc.manuscriptcentral.com/tsed Email: editor_ijse@hotmail.co.uk 
Table 2

Reported participation in types of out-of-classroom science activity

\begin{tabular}{|c|c|c|c|c|}
\hline \multicolumn{2}{|l|}{ Group } & $\begin{array}{l}\text { 'Informal' } \\
\text { science } \\
\text { activities }\end{array}$ & $\begin{array}{l}\text { 'Everyday' } \\
\text { science } \\
\text { engagement }\end{array}$ & $\begin{array}{l}\text { School-led } \\
\text { science } \\
\text { enrichment }\end{array}$ \\
\hline \multicolumn{2}{|l|}{ Overall } & $2.31(.942)$ & $2.47(.979)$ & $1.82(.878)$ \\
\hline \multirow[t]{2}{*}{ Gender } & Female & $2.300(.917)$ & $2.422(.944)$ & $1.794(.844)$ \\
\hline & Male & $2.313(.974)$ & $2.534(1.019)$ & $1.853(.920)$ \\
\hline \multirow{5}{*}{$\begin{array}{l}\text { Year } \\
\text { group }\end{array}$} & Year 7 & $2.557(.939)$ & $2.426(.980)$ & $1.996(.943)$ \\
\hline & Year 8 & $2.374(.957)$ & $2.471(.984)$ & $1.778(.834)$ \\
\hline & Year 9 & $2.257(.895)$ & $2.471(.973)$ & $1.730(.819)$ \\
\hline & Year 10 & $2.134(.861)$ & $2.498(.981)$ & $1.686(.824)$ \\
\hline & Year 11 & $2.112(.911)$ & $2.503(.975)$ & $1.911(.938)$ \\
\hline \multirow[t]{7}{*}{ Ethnicity } & White & $2.342(.910)$ & $2.301(.961)$ & $1.643(.773)$ \\
\hline & South Asian & $2.285(.931)$ & $2.556(.962)$ & $1.890(.888)$ \\
\hline & Black & $2.129(979)$ & $2.532(.964)$ & $1.982(.991)$ \\
\hline & Middle Eastern & $2.392(.947)$ & $2.833(1.107)$ & $1.958(.928)$ \\
\hline & East Asian & $2.415(.999)$ & $2.685(.850)$ & $1.853(.741)$ \\
\hline & Other/mixed & $2.397(.951)$ & $2.530(.965)$ & $1.833(.874)$ \\
\hline & Prefer not to say & $2.322(1.008)$ & $2.464(1.008)$ & $1.927(.954)$ \\
\hline \multirow{5}{*}{$\begin{array}{l}\text { Cultural } \\
\text { capital }\end{array}$} & Very low & $1.528(.597)$ & $1.826(.834)$ & $1.386(.596)$ \\
\hline & Low & $1.979(.784)$ & $2.225(.894)$ & $1.654(.762)$ \\
\hline & Medium & $2.432(.906)$ & $2.540(.934)$ & $1.872(.883)$ \\
\hline & High & $2.617(.933)$ & $2.783(.958)$ & $2.003(.923)$ \\
\hline & Very high & $3.035(.920)$ & $3.005(1.010)$ & $2.204(1.047)$ \\
\hline \multirow[t]{4}{*}{ Attainment } & Top set & $2.366(.942)$ & $2.658(1.006)$ & $1.909(.906)$ \\
\hline & Middle sets & $2.207(.896)$ & $2.331(.919)$ & $1.732(.832)$ \\
\hline & Bottom sets & $2.065(.951)$ & $2.154(.935)$ & $1.661(.830)$ \\
\hline & No sets in school & $2.549(.983)$ & $2.483(.958)$ & $1.887(.908)$ \\
\hline \multirow{3}{*}{$\begin{array}{l}\text { Family } \\
\text { member } \\
\text { working in } \\
\text { science }\end{array}$} & Yes & $2.492(.980)$ & $2.768(1.000)$ & $1.992(.949)$ \\
\hline & Don't know & $2.255(.893)$ & $2.363(.917)$ & $1.759(.832)$ \\
\hline & No & $2.132(.897)$ & $2.216(.909)$ & $1.671(.792)$ \\
\hline
\end{tabular}

URL: http://mc.manuscriptcentral.com/tsed Email: editor_ijse@hotmail.co.uk 
1

2

3

4

5

6

7

8

9

10

11

12

13

14

15

16

17

18

19

20

21

22

23

24

25

26

27

28

29

30

31

32

33

34

35

36

37

38

39

40

41

42

43

44

45

46

47

48

49

50

51

52

53

54

55

56

57

58

59

60

Table 3

Participation in 'Informal' science activities

\begin{tabular}{llll} 
Effect & Coefficient & SE & Effect Size \\
\hline Intercept (constant) & .969 & .048 & N/A \\
Ethnicity - South Asian & -.150 & .027 & -.16 \\
Ethnicity - Black & -.336 & .035 & -.36 \\
Ethnicity - Middle Eastern & -.204 & .054 & -.22 \\
Ethnicity - Other & -.101 & .035 & -.11 \\
Ethnicity - Prefer not to say & -.145 & .037 & -.15 \\
Year 8 & -.103 & .028 & -.11 \\
Year 9 & -.150 & .029 & -.16 \\
Year 10 & -.244 & .030 & -.26 \\
Year 11 & -.332 & .031 & -.35 \\
Cultural capital - very low & -.400 & .040 & -.42 \\
Cultural capital - low & -.216 & .024 & -.23 \\
Cultural capital -high & .080 & .028 & .08 \\
Cultural capital - very high & .272 & .034 & .29 \\
Science set - Top & -.062 & .019 & -.07 \\
'Everyday' science-related activities & .279 & .012 & .30 \\
School-led science enrichment & .250 & .012 & .37 \\
Valuing museums & .176 & .010 & .26 \\
\hline
\end{tabular}

URL: http://mc.manuscriptcentral.com/tsed Email: editor_ijse@hotmail.co.uk 
Table 4

Participation in 'Everyday' science-related activities

\begin{tabular}{llll} 
Effect & Coefficient & SE & Effect Size \\
\hline Intercept (constant) & -.119 & .061 & N/A \\
Gender - Female & -.163 & .021 & -.17 \\
Ethnicity - Black & .074 & .032 & .08 \\
Ethnicity - Chinese/East Asian & .191 & .093 & .20 \\
Year 10 & .151 & .025 & .15 \\
Year 11 & .217 & .027 & .22 \\
Cultural capital - very low & -.107 & .041 & -.11 \\
Cultural capital - low & -.052 & .024 & -.05 \\
Cultural capital - high & .082 & .029 & .08 \\
Cultural capital - very high & .080 & .035 & .08 \\
Family member working in science & .106 & .021 & .11 \\
Science identity* & .326 & .012 & .43 \\
'Informal' science activities & .356 & .012 & .48 \\
Valuing science & .247 & .015 & .28
\end{tabular}

\footnotetext{
* The 'Science identity' composite includes items related to seeing oneself as a 'science person' and holding aspirations to work in science. The 'Valuing science' composite contains items corresponding to positive attitudes towards science inside and outside of the classroom, as well as appreciation of the value of science qualifications and of the work of scientists.
} 
Table 5

1

2

3

4

5

6

7

8

9

10

11

12

13

14

15

16

17

18

19

20

21

22

23

24

25

26

27

28

29

30

31

32

33

34

35

36

37

38

39

40

41

42

43

44

45

46

47

48

49

50

51

52

53

54

55

56

57

58

59

60

Participation in school-led science enrichment

\begin{tabular}{llll} 
Effect & Coefficient & SE & Effect Size \\
\hline Intercept (constant) & .768 & .056 & \\
Gender - Female & -.097 & .021 & -.11 \\
Ethnicity - South Asian & .085 & .027 & .10 \\
Ethnicity - Black & .227 & .035 & .26 \\
Ethnicity - Prefer not to say & .147 & .037 & .17 \\
Year 8 & -.192 & .026 & -.22 \\
Year 9 & -.227 & .027 & -.26 \\
Year 10 & -.217 & .028 & -.25 \\
Cultural capital - very high & .133 & .034 & .15 \\
Family member working in science & .086 & .021 & .10 \\
'Informal' science activities & .301 & .013 & .47 \\
'Everyday' science-related activities & .187 & .012 & .21 \\
\hline
\end{tabular}

URL: http://mc.manuscriptcentral.com/tsed Email: editor_ijse@hotmail.co.uk 
Table 6

Summary of rotated factor loadings for components related to science participation outside of the science classroom

\begin{tabular}{|c|c|c|c|}
\hline Item & $\begin{array}{l}\text { School-led } \\
\text { science } \\
\text { enrichment }\end{array}$ & $\begin{array}{l}\text { 'Informal' } \\
\text { science } \\
\text { activities }\end{array}$ & $\begin{array}{c}\text { 'Everyday' } \\
\text { science } \\
\text { engagement }\end{array}$ \\
\hline Take a science-related school trip & .819 & & \\
\hline Take a school trip to a museum & .775 & & \\
\hline $\begin{array}{l}\text { Attend a visitor talk or presentation } \\
\text { about science }\end{array}$ & .635 & & \\
\hline $\begin{array}{l}\text { Go to a lunchtime or after-school } \\
\text { science club }\end{array}$ & .504 & & \\
\hline (How often) Fix or build things & & .714 & \\
\hline Visit a zoo or an aquarium & & .694 & \\
\hline Nature walk or similar & & .683 & \\
\hline Do experiments or use science kits & & 646 & \\
\hline Program computers & & .615 & \\
\hline Go to a science centre, science & & .597 & \\
\hline $\begin{array}{l}\text { museum or planetarium } \\
\text { (How often) watch science TV } \\
\text { programmes }\end{array}$ & & & .675 \\
\hline $\begin{array}{l}\text { Read books or magazines about } \\
\text { science }\end{array}$ & & & .608 \\
\hline Go online to find out about science & & & .606 \\
\hline $\begin{array}{l}\text { Watch other TV programmes with } \\
\text { some science in them }\end{array}$ & & & .587 \\
\hline $\begin{array}{l}\text { Talk about science with others } \\
\text { (when not in school) }\end{array}$ & & & .456 \\
\hline $\begin{array}{l}\text { Cronbach's alpha (for } \\
\text { components) }\end{array}$ & .742 & .814 & .793 \\
\hline
\end{tabular}


Table 7

Background/demographic variables used in all models

\begin{tabular}{cc} 
Category & Variables \\
\hline Gender & Female \\
(Ref: Male) &
\end{tabular}

South Asian

Black

Ethnicity

Chinese/East Asian

(Ref: White)

Middle Eastern

Other (incl Mixed race)

Prefer not to say

Year 8

Year group

Year 9

(Ref: Year 7)

Year 10

Year 11

Cultural capital

Very low

(Ref: Medium)

Low

High

Very high

Science set

Top

(Ref: Middle sets)

Bottom

No sets for science (at my school)

Family member who works in science

Yes

\title{
(Ref: 'No')
}

\begin{abstract}
N.B. Reference categories are in brackets in the 'Categories' column above. All of the variables in the 'Variables' column above were created as dummy variables and entered into the MLM analysis. Those that were statistically significant (i.e. closely related to the dependent variable) are included in Tables 3, 4 and 5.
\end{abstract}

